Communication

\title{
A Technique for Estimating Greenhouse Gas Exchange Adjacent Cattle Feedlots
}

\author{
Sean M. McGinn ${ }^{1, *}$ and Thomas K. Flesch ${ }^{2}$ \\ 1 Agriculture and Agri-Food Canada, Lethbridge, AB T1J 4B1, Canada \\ 2 Department of Earth and Atmospheric Sciences, University of Alberta, Edmonton, AB T6G 2E3, Canada; \\ tflesch@ualberta.ca \\ * Correspondence: sean.mcginn@agr.gc.ca
}

Received: 28 February 2018; Accepted: 6 April 2018; Published: 9 April 2018

\begin{abstract}
Concentrated animal feeding operations (CAFO) such as open-air beef cattle feedlots are known 'hot spots' of emissions of numerous gases including the major greenhouse gases methane, nitrous oxide, and carbon dioxide. Some work has documented CAFOs to derive typical emission factors, but few studies have looked beyond the CAFO to the local landscape to derive the net off-farm emissions. To address the net emissions, the exchange of gases downwind of CAFOs is required, determined in part by the air quality of the gas plume from the CAFO and the characteristics of the underlying surface. Our study measured these downwind fluxes at an open-air beef cattle feedlot using an open-path Fourier Transform Infrared detector and a flux-gradient method. The results showed the dynamic response of fluxes to gas concentration (fresh air or feedlot air) and surface condition (actively growing crop and tilled stubble). These results shed light on the pathways of greenhouse gas flow near a CAFO source, and showed that solely measuring source emissions from a CAFO would lead to errors when developing emission factors.
\end{abstract}

Keywords: deposition; emission; methane; nitrous oxide; cattle; flux gradient

\section{Introduction}

Concentrated animal feeding operations (CAFO) like beef cattle feedlots are known sources of several important gases including ammonia $\left(\mathrm{NH}_{3}\right)$ and the three major greenhouse gases (GHG), i.e., methane $\left(\mathrm{CH}_{4}\right)$, nitrous oxide $\left(\mathrm{N}_{2} \mathrm{O}\right)$, and carbon dioxide $\left(\mathrm{CO}_{2}\right)$. These GHG are of interest since they accumulate in our atmosphere and contribute to global warming. For a feedlot, the $\mathrm{N}_{2} \mathrm{O}$ and a small fraction of $\mathrm{CH}_{4}$ are from accumulated manure, whereas, most of the $\mathrm{CH}_{4}$ and $\mathrm{CO}_{2}$ are emitted from the eructation and respiration of the animals. In the beef cattle sector, the emission of $\mathrm{CH}_{4}$ by ruminates is an important environmental factor that remains to be mitigated to truly make this sector environmentally sustainable. Currently, it is estimated [1] that livestock are responsible for 5.6 to $7.5 \mathrm{Gt}$ of $\mathrm{CO}_{2}$ equivalent each year and a significant portion of the reduction potential in agriculture is attributed to livestock. When considering the environmental impact of gas emissions from CAFOs, the overwhelming focus has been on considering gas fluxes from the CAFO proper. Less attention is given to the environment immediately surrounding the CAFO. As gas concentrations downwind of a CAFO can be very high, they can induce surface fluxes that are very different from landscapes further downwind, and these fluxes may create a more complex picture of the impact of CAFOs. Although some attention has been given to the deposition of $\mathrm{NH}_{3}$ close to CAFO sources [2-4], little information exists on livestock GHG fluxes close to CAFOs. Such work would better define the net emissions factors for CAFOs used in deriving GHG inventories and in measuring GHG mitigation strategies. 
Estimating the net flux of GHG to landscapes surrounding CAFO sources can be done using several approaches including various micrometorological methods [5,6]. Most notable is the eddy covariance method, which requires fast response sensors to capture fluctuations in the vertical air movement (eddies) and the accompanying 'instantaneous' gas concentration. Another micrometeorological approach is the flux-gradient (FG) method, which estimates the flux (either upward or downward) based on the measurement of the vertical gradient in gas concentration above the surface [5] without the need of fast-response sensors. Like the eddy covariance method, the FG approach is recognized to accurately monitor gas emissions without disruption to the surface environment and can be used to continuously evaluate the short- or long-term fluxes of a gas at a source. To determine the GHG balance of CAFOs such as beef cattle feedlots, it is necessary to document both the source area fluxes and local (on-farm) deposition and emission of these GHGs. The goal of our study was to present a novel approach to evaluate the flux of $\mathrm{CH}_{4}, \mathrm{~N}_{2} \mathrm{O}$, and $\mathrm{CO}_{2}$ on land surrounding a feedlot by measuring the deposition or emission. This study provides valuable insights in the dynamics of gas flux at beef cattle feedlots.

\section{Materials and Methods}

\subsection{Study Site}

The study was conducted over two 10-day campaigns in 2015 (summer campaign 23 June-3 July; autumn campaign 12-23 October). A commercial feedlot in the vicinity of Lethbridge, Alberta $\left(49.69349^{\circ} \mathrm{N}, 112.84184^{\circ} \mathrm{W}\right)$ was selected for measurement based on the access and configuration of the site, e.g., flat and open fields adjacent to the feedlot that were conducive to micrometeorological techniques. Measurements in both campaigns took place in the field immediately east of the feedlot (Figure 1). The surface of this eastern field was very different for each campaign. During the first campaign (summer), the fluxes were measured above a rapidly growing (and well-watered) winter wheat crop. By the second campaign (autumn), the field was tilled, and the stubble partially incorporated. Throughout our analysis, we differentiated two different situations: either the field was categorized as being downwind (westerly winds) or being upwind (easterly winds) of the feedlot. We will then refer to upwind fluxes and downwind fluxes, or to "upwind" and "downwind" scenarios.

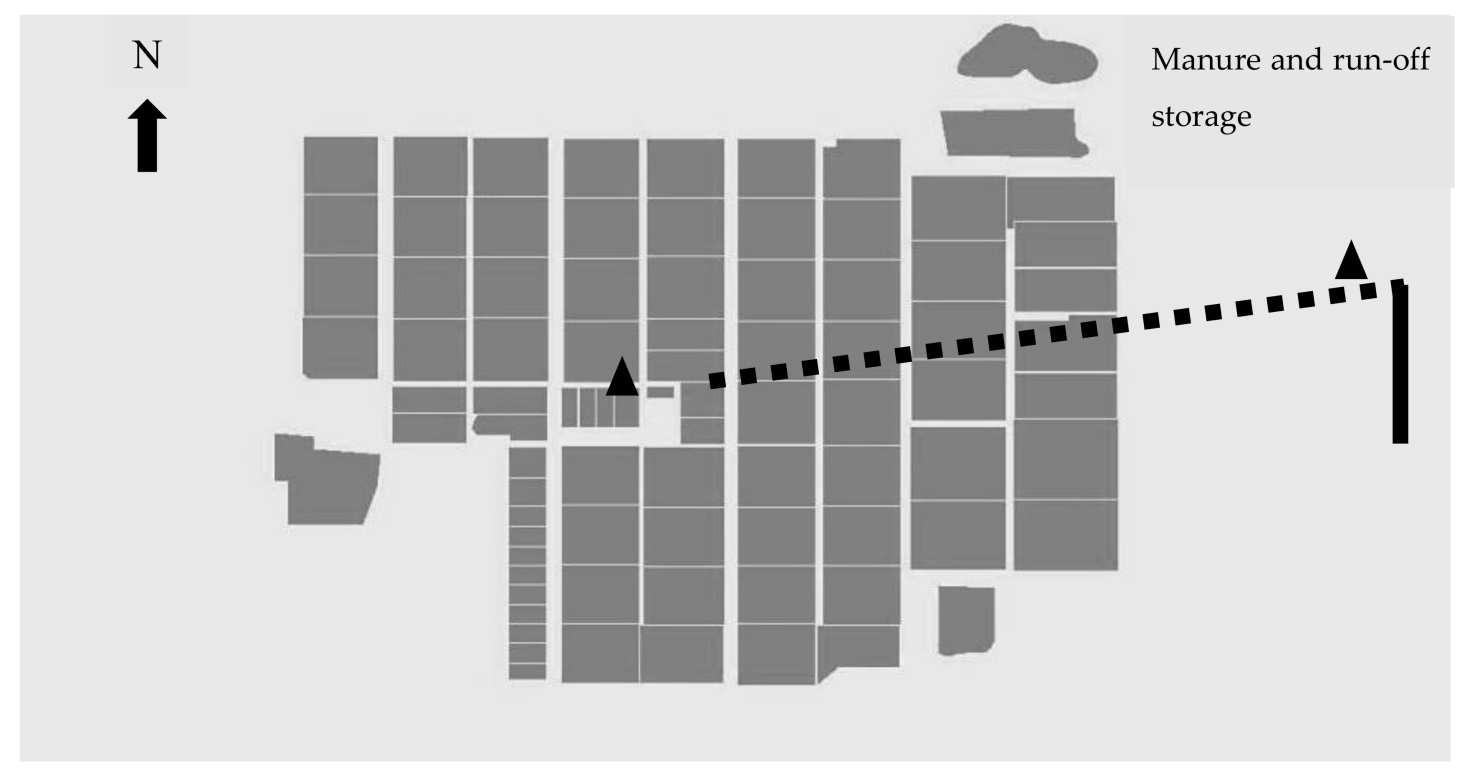

Figure 1. Study site with a Fourier Transform Infrared detector (FTIR) in the east field using long path (dashed) and slanted paths (solid) and the location of two sonic anemometers (triangles). 


\subsection{Measuring Gas Concentration}

All gas concentrations were measured by using an open-path Fourier Transform Infrared (OP-FTIR) detector (components assembled and software developed at the University of Wollongong, New South Wales, Australia) that included a spectrometer (Matrix-M IR cube, Bruker Optik, Ettlingen, Germany) and software (MALT, Multiple Atmospheric Layer Transmission) that measured $\mathrm{CH}_{4}$, $\mathrm{N}_{2} \mathrm{O}$, and $\mathrm{CO}_{2}$ concentrations simultaneously [7-9]. The OP-FTIR measures the long-path average concentration of several gases by analyzing the spectrum of an infra-red beam that has traversed an atmospheric path [10]. The beam travels from the OP-FTIR spectrometer to a retroreflector array and then back to the FTIR detector. The spectrometer and detector were mounted on a stepping motor under the control of a computer; this allowed the unit to be automatically aimed to different retroreflectors sequentially. The two $50 \mathrm{~m}$ paths of the OP-FTIR were vertically slanted (summer path heights were 1.6-2.05 m and 1.6-4.15 m; fall heights were 1.6-0.72 and 1.6-2.7) in the east field, orientated north-south. These paths were $165 \mathrm{~m}$ from the feedlot. The spectrometer recorded an infrared absorption spectrum from repeated measurements over a 2-min measurement interval. A sonic anemometer (CSAT3, Campbell Scientific) was located in: (1) the east field close to the OP-FTIR at a height of $3 \mathrm{~m}$, which recorded the three components of the wind $(\mathrm{u}, \mathrm{v}, \mathrm{and} \mathrm{w})$ and their cross products at $10 \mathrm{~Hz}$; and (2) the central portion of the feedlot just above the $3 \mathrm{~m}$ height of the shelter fences. The east-field sonic anemometer was used to calculate gas fluxes in the field, and a feedlot sonic anemometer was used to calculate the emissions within the feedlot.

\subsection{Estimating Deposition/Emission}

The measured OP-FTIR gas mixing ratio (ppmv) data were used to calculate the emission or deposition of gases at the surface in a field adjacent to the feedlots using a Flux Gradient (FG) method. The flux of gas $s\left(F_{s} ; \mathrm{g} \mathrm{m}^{-2} \mathrm{~s}^{-1}\right.$ is calculated by using the difference in the mixing ratio (converted to concentration $C_{\mathrm{s}}$ ) at two heights separated by $z(\mathrm{~m})$ :

$$
F_{S}=-K_{s} \rho_{a} \frac{M_{s}}{M_{a}} \frac{\Delta C_{s}}{\Delta z}
$$

where $K_{\mathrm{s}}\left(\mathrm{m}^{2} \mathrm{~s}^{-1}\right)$ is the diffusivity of gas $s ; \rho_{\mathrm{a}}\left(\mathrm{g} \mathrm{m}^{-3}\right)$ is the density of dry air; $M_{\mathrm{s}}$ and $M_{\mathrm{a}}$ are the molr masses of gas $s$ and dry air (a); and $\Delta C_{s}$ is the difference in volumetric mixing ratio (relative to dry air). Using this equation, Flesch et al. (2016) derived a working formula for the flux $Q_{\mathrm{FG}}\left(\mathrm{g} \mathrm{m}^{-2} \mathrm{~s}^{-1}\right)$ from the difference in concentration $\Delta C_{\mathrm{L}}$ between the two slant OP-FTIR paths (corrected for dry air):

$$
Q_{F G}=-\frac{k_{v} \rho_{a} u_{*}}{S c} \frac{M_{S}}{M_{a}} \frac{\Delta C_{L}}{\frac{1}{\ell_{\text {path }}} \int_{x 1}^{x 2}\left[\ln \left(\frac{z_{p 2}}{z_{p 1}}\right)-\Psi_{m}\left(\frac{z_{p 2}}{L}\right)+\Psi_{m}\left(\frac{z_{p 1}}{L}\right)\right] d x}
$$

where $k_{\mathrm{v}}$ is von Karman's constant (0.4); $S c$ is the Schmidt number (0.64; see [11]); $u_{*}\left(\mathrm{~m} \mathrm{~s}^{-1}\right)$ is the friction velocity (from a 3-D sonic anemometer); $x(\mathrm{~m})$ is the along-path horizontal coordinate ( $x_{1}$ and $x_{2}$ are the positions of the OP-FTIR sensor and the reflector); $z_{\mathrm{p}}(\mathrm{m})$ is the path height above ground of the two paths at $x ; \ell_{\text {path }}(\mathrm{m})$ is the total path length of the two slanted paths; and $\Psi_{\mathrm{m}}$ is the stability correction based on the Obukhov length $L(\mathrm{~m})$ :

$$
\begin{array}{rlrl}
\Psi_{m}\left(\frac{z}{L}\right) & =-5 \frac{z}{L} & & (L>0: \text { stable }) \\
& =2 \ln \left[\frac{1+y}{2}\right]+\ln \left[\frac{1+y^{2}}{2}\right]-2 \tan ^{-1} y+\pi / 2 & (L<0: \text { unstable })
\end{array}
$$

where $y=(1-16 z / L)^{0.25}$.

In Table 1, the positive values of $Q_{\mathrm{FG}}$ indicate emissions from the surface to the atmosphere, e.g., the lower path concentration was greater than the upper path concentration. Negative $Q_{\mathrm{FG}}$ 
represents the gas absorption by the surface. Calculations of $Q_{\mathrm{FG}}$ were not made when $u *<0.05 \mathrm{~m} \mathrm{~s}^{-1}$, recognizing the large uncertainty in the underlying assumptions for very light winds.

A third sequential OP-FTIR path was set to transverse to a retroreflector (consisting of 92 cubes) that was mounted on scaffolding near the middle of the feedlot. The path length was $500 \mathrm{~m}$. This slanted line-averaged concentration (height change from $1.6 \mathrm{~m}$ at OP-FTIR to $3.1 \mathrm{~m}$ at retroreflector) was used to calculate the emission rates from the feedlot using the inverse dispersion method (IDM) with WindTrax software (version 2.0.8.8; Thunder Beach Scientific (Edmonton, Canada)) following a previous protocol [12]. WindTrax is well recognized as a useful tool for estimating emissions from feedlots $[5,13]$. In this model, the gas plume from the feedlot is characterized (using wind statistics) by tracking 600,000 trajectories representing the source-to-detection transfer of the target gas. The feedlot was mapped with a GPS system, and the pen blocks were represented as a collection of homogeneous area sources. The WindTrax simulated plume was used to predict an emission-to-concentration relationship $(Q / C)_{\text {sim. }}$. This simulated relationship was used with measured 10-min gas concentrations to infer the daily emission of each gas.

The average daily emission was calculated by deriving the 3-h bin average (where the data allowed) and then averaged for the daily averages from the bin data.

\section{Results}

For the summer campaign, the winter wheat crop in the measurement field was actively growing; while for the fall campaign, the field surface consisted of stubble that was partly buried following tillage. In the upwind scenario (easterly winds bring fresh air over the site), $\mathrm{CH}_{4}$ was emitted from the field during both summer and autumn (Table 1). Emissions were greater for the growing crop than for the tilled stubble surface ( 540 vs. $159 \mathrm{~g} \mathrm{ha}^{-1} \mathrm{~d}^{-1}$ ). For the downwind scenario (westerly air flow from the feedlot), the tilled stubble surface was a large source of $\mathrm{CH}_{4}\left(1360 \mathrm{~g} \mathrm{ha}^{-1} \mathrm{~d}^{-1}\right)$. However, the growing crop downwind of the feedlot was a large sink for $\mathrm{CH}_{4}$, i.e., deposition of $1296 \mathrm{~g} \mathrm{ha}^{-1} \mathrm{~d}^{-1}$.

Table 1. Fluxes ( $\mathrm{g} \mathrm{ha}^{-1} \mathrm{~d}^{-1}$ ) for growing crop (upper table) and tilled stubble (lower table) where bold values are the deposition. Upwind refers to the air flow entering the feedlot and downwind refers to air flow off the feedlot.

\begin{tabular}{ccc}
\hline Gas & Upwind & Downwind \\
\hline $\mathrm{CH}_{4}$ & $540 \pm 466$ & $-1296 \pm 850$ \\
$\mathrm{~N}_{2} \mathrm{O}$ & $43 \pm 101$ & $-0.5 \pm 270$ \\
$\mathrm{CO}_{2}$ & $111,000 \pm 357,000$ & $-194,000 \pm 153,000$ \\
$\mathrm{H}_{2} \mathrm{O}^{+}$ & $14.5 \pm 0.4 .4$ & $7.0 \pm 5.8$ \\
$\mathrm{CH}_{4}$ & $159 \pm 334$ & $1360 \pm 1910$ \\
$\mathrm{~N}_{2} \mathrm{O}$ & $-17 \pm 77$ & $59 \pm 77$ \\
$\mathrm{CO}_{2}$ & $-13,000 \pm 134,000$ & $216,000 \pm 153,000$ \\
$\mathrm{H}_{2} \mathrm{O}^{+}$ & $0.74 \pm 0.36$ & $1.45 \pm 0.38$ \\
\hline \multicolumn{3}{c}{ ' }
\end{tabular}

The situation for $\mathrm{N}_{2} \mathrm{O}$ was different than that found for $\mathrm{CH}_{4}$ at the upwind location, where the summer crop surface was an emission source of $\mathrm{N}_{2} \mathrm{O}\left(43 \mathrm{~g} \mathrm{ha}^{-1} \mathrm{~d}^{-1}\right)$, but became a sink for the fall tilled surface $\left(-17 \mathrm{~g} \mathrm{ha}^{-1} \mathrm{~d}^{-1}\right)$. However, similar to $\mathrm{CH}_{4}$ for the downwind scenario, the growing summer crop surface was a sink for $\mathrm{N}_{2} \mathrm{O}$ (slight $-0.5 \mathrm{~g} \mathrm{ha}^{-1} \mathrm{~d}^{-1}$ ) and the tilled surface in autumn was a source of $\mathrm{N}_{2} \mathrm{O}\left(59 \mathrm{~g} \mathrm{ha}^{-1} \mathrm{~d}^{-1}\right)$.

Carbon dioxide flux for the upwind scenario characterized the crop as a source (at 111,000 $\left.\mathrm{g} \mathrm{ha}^{-1} \mathrm{~d}^{-1}\right)$ while the tilled surface was a sink $\left(13,000 \mathrm{~g} \mathrm{ha}^{-1} \mathrm{~d}^{-1}\right)$. For the downwind scenario, $\mathrm{CO}_{2}$ was reversed when compared to the upwind scenario where the crop was a sink $\left(194,000 \mathrm{~g} \mathrm{ha}^{-1} \mathrm{~d}^{-1}\right)$ while the tilled surface was a source $\left(216,000 \mathrm{~g} \mathrm{ha}^{-1} \mathrm{~d}^{-1}\right)$. We noted that the $\mathrm{CO}_{2}$ fluxes were highly variable (e.g., strong diel cycles), with a standard deviation of the flux data that was much larger than the mean. 
As supplementary information, the flux of water was also measured for the crop $\left(7\right.$ and $\left.14 \mathrm{~mm} \mathrm{~d}^{-1}\right)$ and the tilled surfaces ( 0.7 and $\left.1.4 \mathrm{~mm} \mathrm{~d}^{-1}\right)$ at the upwind and downwind locations, respectively. The greater evapotranspiration value of the crop surface was expected given the field was irrigated periodically during the summer only. This expected result contributed to our confidence in the new approach we presented in this paper.

The feedlot was a large source for all gases measured in both campaigns (Table 2). There was a decline in $\mathrm{CH}_{4}$ emissions from summer to autumn (171 to $93 \mathrm{~g}$ animal $\left.^{-1} \mathrm{~d}^{-1}\right)$, but $\mathrm{N}_{2} \mathrm{O}$ was fairly constant (11.5 and $12.3 \mathrm{~g}$ animal $^{-1} \mathrm{~d}^{-1}$ ) between the seasons. Carbon dioxide deposition/emission data were 31,200 vs. $23,300 \mathrm{~g}$ animal $^{-1} \mathrm{~d}^{-1}$; these were previously reported [14].

Table 2. Daily gas emissions ( \pm standard error) from the feedlot (g per animal) for a growing crop (June/July) and a tilled stubble surface (October).

\begin{tabular}{|c|c|c|}
\hline \multirow{2}{*}{ Gas } & \multicolumn{2}{|c|}{ Feedlot Emission $\left(\mathrm{g} \text { animal }^{-1} \mathrm{~d}^{-1}\right)^{\dagger}$} \\
\hline & Summer & Fall \\
\hline $\mathrm{CH}_{4}$ & $171 \pm 17.6$ & $93 \pm 7.3$ \\
\hline $\mathrm{N}_{2} \mathrm{O}$ & $11.2 \pm 0.9$ & $12.3 \pm 1.0$ \\
\hline $\mathrm{CO}_{2}$ & $23,306^{\mathrm{F}} \pm 1905$ & $31,226+ \pm 1911$ \\
\hline
\end{tabular}

\section{Discussion}

The FG method was used with the short vertical OP-FTIR gradients and it was assumed that the surrounding surface was a spatially large and horizontally homogeneous gas source (or sink), so that the gas concentration was horizontally uniform throughout the measurement location. At our measurement site, this was expected when the wind direction was easterly, delivering "fresh" air over our large and uniform field. However, with a west wind the air flow immediately downwind of the feedlot was not horizontally homogeneous, as the concentration of gases from the feedlot became diluted with distance from the source. As a result, the vertical concentration gradient measured downwind no longer corresponded directly to the underlying surface flux (in the measurement footprint area). The presence of flux divergence downwind of the feedlot creates an "advection error" in the FG flux calculations [2]. This error complicates the interpretation of fluxes downwind of the feedlot. However, its impact declines with distance from the feedlot. The results reported here ignored the advection error. To better understand the importance of this error on our calculations, we looked at associated $\mathrm{NH}_{3}$ data [15]. These summer gradient data were evaluated using the WindTrax IDM that included dry deposition. This indicated the advection error was less than $5 \%$ of the FG derived surface fluxes for the downwind calculations. The potential for error suggests that in the future, the evaluation of concentration gradients (to derive a flux) would better be made using a dispersion model that accounts for flux divergence. In the future we intend to implement an IDM approach where the downwind concentrations are input to a dispersion model, which would then calculate a surface flux.

The feedlot emission rate measured using the $500 \mathrm{~m}$ slanted pathway terminating in the feedlot (Table 2; $\mathrm{CH}_{4}$ at $171 \mathrm{~g}$ animal $^{-1} \mathrm{~d}^{-1}, \mathrm{~N}_{2} \mathrm{O}$ at $11.5 \mathrm{~g}$ animal $^{-1} \mathrm{~d}^{-1}$, and $\mathrm{CO}_{2}$ at $23,300 \mathrm{~g}$ animal $^{-1} \mathrm{~d}^{-1}$ ) must be treated with caution since the downwind deposition was not included in the feedlot emissions. In the autumn, when a tilled stubble surface existed, there was no deposition and so the emission rates of all three GHGs $\left(\mathrm{CH}_{4}\right.$ at $93 \mathrm{~g}$ animal $^{-1} \mathrm{~d}^{-1} ; \mathrm{N}_{2} \mathrm{O}$ at $12.3 \mathrm{~g}$ animal $^{-1} \mathrm{~d}^{-1}$; and $\mathrm{CO}_{2}$ at 31,200 $\mathrm{g}$ animal $^{-1} \mathrm{~d}^{-1}$ ) better reflected the in-feedlot emissions. Using the FG data on deposition rate, it was estimated that the percentage of the feedlot emissions deposited within $500 \mathrm{~m}$ of the feedlot was 1.5 for $\mathrm{CH}_{4}$. This percentage was less than 1 for the deposition rate of $\mathrm{N}_{2} \mathrm{O}$ and 1.6 for $\mathrm{CO}_{2}$ at the downwind site of our study.

The $\mathrm{CH}_{4}$ emission rate of $171 \mathrm{~g}_{\text {animal }}{ }^{-1} \mathrm{~d}^{-1}$ was similar to other reported beef cattle feedlot rates, e.g., $154 \mathrm{~g}$ animal $^{-1} \mathrm{~d}^{-1}$ [16]. Our $\mathrm{N}_{2} \mathrm{O}$ emission rates of 8.0 to $12.3 \mathrm{~g}$ animal $^{-1} \mathrm{~d}^{-1}$ 
exceeded the reported the rate of $0.7 \mathrm{~g}_{\text {animal }}^{-1} \mathrm{~d}^{-1}$ [17] and was less than the reported rate of $26 \mathrm{~g}_{\text {animal }}{ }^{-1} \mathrm{~d}^{-1}[18]$.

\section{Conclusions}

The focus of most studies that measure GHG at CAFOs typically neglect the interactions of the surrounding landscape and the source plume. Omitting this interaction can lead to over-estimating the emissions factor for CAFOs. Our study suggested that this error was greater for downwind fields with a well-watered growing crop as opposed to a bare soil surface. We presented a combination of two micrometeorological methods and the use of slanted vertical line-averaged paths using an OP-FTIR detector located adjacent to a cattle feedlot CAFO to evaluate the gas exchange dynamics of the local surface zone.

Acknowledgments: This study was funded by the Alberta Livestock and Meat Agency (\#2015E004R).

Author Contributions: S.M.M. designed the studies, helped collect and interpret the data, and wrote the draft. T.K.F. helped with data collection and analysis.

Conflicts of Interest: The authors declare no conflict of interest.

\begin{tabular}{ll}
\multicolumn{2}{l}{ Abbreviations } \\
CAFO & concentrated animal feeding operation \\
FG & flux gradient \\
GHG & greenhouse gas \\
IDM & inverse dispersion method \\
OP-FTIR & open-path Fourier Infrared
\end{tabular}

\section{References}

1. Herrero, M.; Henderson, B.; Havlik, P.; Thornton, P.K.; Conant, R.T.; Smith, P.; Wirsenius, S.; Hristov, A.N.; Gerber, P.; Gill, M.; et al. Greenhouse gas mitigation potentials in the livestock sector. Nat. Clim. Chang. 2016, 6, 452-461. [CrossRef]

2. Loubet, B.; Milford, C.; Hensen, A.; Daemmgen, U.; Erisman, J.P.; Cellier, P.; Sutton, M.T. Advection of $\mathrm{NH}_{3}$ over a pasture field and its effect on gradient flux measurements. Biogeosciences 2009, 6, 1295-1310. [CrossRef]

3. Hristov, A.N.; Hanigan, M.; Coe, A.; Todd, R.; McAllister, T.A.; Ndegwa, P.M.; Rotz, A. Review: Ammonia emission from dairy farms and beef feedlots. Can. J. Anim. Sci. 2011, 91, 1-35. [CrossRef]

4. McGinn, S.M.; Janzen, H.H.; Coates, T.W.; Beauchemin, K.A.; Flesch, T.K. Ammonia emission from a beef cattle feedlot and its local dry deposition and re-emission. J. Environ. Qual. 2016, 45, 1178-1185. [CrossRef] [PubMed]

5. Harper, L.A.; Denmead, O.T.; Flesch, T.K. Micrometeorological techniques for measurement of enteric greenhouse gas emissions. Anim. Feed Sci. Technol. 2011, 166-167, 227-239. [CrossRef]

6. McGinn, S.M. Developments in micrometeorological methods for methane measurements. Animal 2013, 7, 386-393. [CrossRef] [PubMed]

7. Griffith, D.W.T. Synthetic calibration and quantitative analysis of gas-phase FT-IR spectra. Appl. Spectrosc. 1996, 50, 59-70. [CrossRef]

8. Griffith, D.W.T.; Deutscher, N.M.; Caldow, C.G.R.; Kettlewell, G.; Riggenbach, M.; Hammer, S. A Fourier transform infrared trace gas analyser for atmospheric applications. Atmos. Meas. Tech. 2012, 5, 2481-2498. [CrossRef]

9. Smith, T.E.L.; Wooster, M.J.; Tattaris, M.; Griffith, D.W.T. Absolute accuracy evaluation and sensitivity analysis of OP-FTIR NLS retrievals of $\mathrm{CO}_{2}, \mathrm{CH}_{4}$ and $\mathrm{CO}$ over concentrations ranging from those of ambient atmospheres to highly polluted plumes. Atmos. Meas. Tech. 2011, 4, 97-116. [CrossRef]

10. Bai, M. Methane Emissions from Livestock Measured by Novel Spectroscopic Techniques. Ph.D. Thesis, University of Wollongong, Wollongong, Australia, 2010. 
11. Flesch, T.K.; Prueger, J.H.; Hatfield, J.L. Turbulent Schmidt number from a tracer experiment. Agric. For. Meteorol. 2002, 111, 299-302. [CrossRef]

12. Flesch, T.K.; McGinn, S.M.; Chen, D.; Wilson, J.D.; Desjardins, R.L. Data filtering for inverse dispersion emission calculations. Agric. For. Meteorol. 2014, 198-199, 1-6. [CrossRef]

13. Flesch, T.K.; Wilson, J.D.; Harper, L.A.; Todd, R.W.; Cole, N.A. Determining ammonia emissions from a cattle feedlot with an inverse dispersion technique. Agric. For. Meteorol. 2007, 144, 139-155. [CrossRef]

14. McGinn, S.M.; Flesch, T.K. Ammonia and greenhouse gas emissions at beef cattle feedlots in Alberta Canada. Agric. For. Meteorol. 2018, in press. [CrossRef]

15. McGinn, S.M. Developments in micrometeorological methods for methane measurements. Animal 2013, 7, 386-393. [CrossRef] [PubMed]

16. Bai, M.; Flesch, T.K.; McGinn, S.M.; Chen, D. A snapshot of greenhouse gas emissions from a cattle feedlot. J. Environ. Qual. 2015, 44, 1974-1978. [CrossRef] [PubMed]

17. Borhan, M.S.; Capareda, S.; Mukhtar, S.; Faulkner, W.B.; McGee, R.; Parnell, C.B. Greenhouse gas emissions from ground level area sources in dairy and cattle feedyard operations. Atmosphere 2011, 2, 303-329. [CrossRef]

18. Rahman, S.; Borhan, M.S.; Swanson, K. Greenhouse gas emissions from beef cattle pen surfaces in North Dakota. Environ. Tech. 2013, 34, 1239-1246. [CrossRef] [PubMed]

(C) 2018 by the authors. Licensee MDPI, Basel, Switzerland. This article is an open access article distributed under the terms and conditions of the Creative Commons Attribution (CC BY) license (http:/ / creativecommons.org/licenses/by/4.0/). 